\title{
APLICAÇÃO DA ESCALA TRL E DE MÉTODOS DE DESENVOLVIMENTO DE PRODUTO EM PROJETO DE PESQUISA NA UNIVERSIDADE: UM ESTUDO DE CASO
}

Leonardo Aguayo (aguayo@ unb.br) - Universidade de Brasília/FGA, Eng. Eletrônica

Euler Vilhena De Garcia (evgarcia@ unb.br) - Universidade de Brasília/FGA, Eng. Eletrônica

Fabio Cordeiro de Lisboa (abiolisboa@ unb.br) - Universidade de Brasília/FGA, Eng. Automotiva

Wellington Avelino do Amaral (waamaral@unb.br) - Universidade de Brasília/FGA, Eng. Eletrônica

Adoniran Judson de Barros Braga (braga@unb.br) - Universidade de Brasília/FT, Departamento de Engenharia Elétrica

Luiza Carneiro Cezareo (luiza_cezario@ hotmail.com) - Universidade de Brasília/FGA, Eng. Eletrônica Lidiane Laís Santos (idiane.lais7@gmail.com) - Universidade de Brasília/FGA, Eng. Aeroespacial

\section{RESUMO}

O trabalho apresenta ume estudo de caso de um projeto de pesquisa com foco no desenvolvimento da prova de conceito e prototipagem de um sistema de comunicação. A partir de um mapeamento entre as atividades do projeto de pesquisa e a escala TRL (Technology Readiness Level- Nível de Maturidade Tecnológica), explicitam-se os benefícios acadêmicos obtidos do emprego dos protótipos, simuladores construídos e de técnicas de Processo de desenvolvimento de produtos (PDP), adotadas no projeto. Apresenta-se, ainda, uma proposta para adoção do indicador TRL para direcionamento da elaboração de planos de trabalho em projetos acadêmicos de pesquisa em engenharia.

Palavras chave: TRL; pesquisa; transferência de tecnologia; estudo de caso. 


\section{INTRODUÇÃO}

Os processos de desenvolvimento de produto (PDP) registrados na literatura clássica, como os descritos em ROZENFELD et al., (2006) e ULRICH; EPPINGER (2004), tipicamente têm como foco principal o desenvolvimento de produtos por empresas. A lógica de integração e transferência de informação, subjacente aos procedimentos de Engenharia Simultânea e "Design for X" (DFX) fica explícita no encadeamento das etapas do PDP, na construção e gestão de equipes multidisciplinares, e no uso intensivo de ferramentas como as Computer Aided Engineering (CAE) e o Computer Aided Design(CAD) (BACK 2008, MADUREIRA, 2014).

A Figura 1 apresenta o sequenciamento típico para as etapas tradicionais de desenvolvimento de produtos, na qual as nomenclaturas de projeto conceitual, preliminar e detalhado representam os sucessivos graus de detalhamento das atividades de projeto, com o auxílio de protótipos físicos ou virtuais, obtidos por meio de simulação computacional.

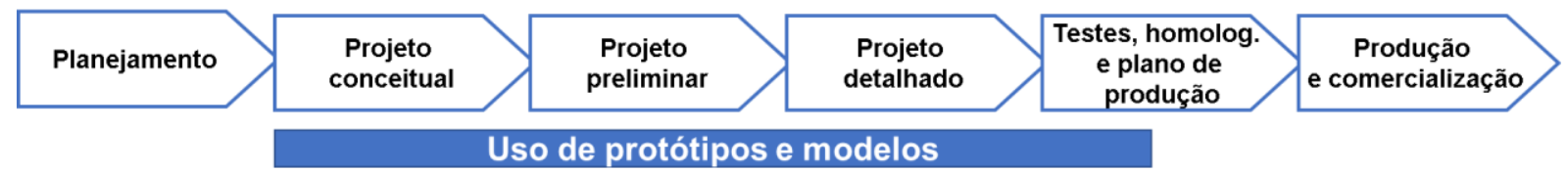

FIGURA 1 - Etapas típicas de planejamento de produto e relação com o uso de protótipos e simulações. Adaptado de ULRICH e EPPINGER (2004).

A verticalização das atividades necessárias para a implantação e operação de todo o PDP por uma única empresa pode ser inviável, havendo espaço para especialização de entregas por atividades por entidades distintas. Este fato pode ser verificado pela presença de design houses, nas etapas iniciais, e pela terceirização da manufatura e testes nas etapas finais do processo.

Uma das fontes de conhecimento tecnológico que podem auxiliar no desenvolvimento de produtos encontra-se no meio acadêmico. Na relação academia-setor industrial, há possibilidade de forte integração entre as duas entidades, em particular nas fases iniciais do processo, quando o esforço maior está concentrado nas etapas do projeto conceitual e preliminar, antes das atividades concernentes ao projeto detalhado. 
Sob a ótica do uso da Engenharia Simultânea, é bem documentada a boa prática da construção de protótipos logo nas fases iniciais do projeto, com vistas à manutenção não apenas do conceito primário do produto, mas também da consistência entre os requisitos técnicos, econômicos e financeiros ao longo de todo o PDP (BACK et al., 2008).

Neste trabalho, apresenta-se o estudo de caso de um projeto de pesquisa realizado na Universidade de Brasília (UnB) financiado pelo setor produtivo, onde a aplicação de técnicas tradicionais de PDP trouxe benefícios mútuos para os envolvidos. Em particular, aborda-se especificamente a questão do uso de protótipos e simuladores para um estudo de caso em projetos de pesquisa em sistemas de comunicação. Dentro das atividades acadêmicas, aplicaram-se as práticas comuns de manutenção de qualidade na construção de provas de conceito em ambiente laboratorial, resultantes de estudos executados por professores, alunos de graduação e de pós-graduação.

O restante do texto divide-se da seguinte forma: na Seção 2 apresenta-se um mapeamento entre as atividades do projeto de pesquisa e a escala TRL, onde o contexto é o de projeto de sistemas de comunicação, onde se discute como a escala TRL foi utilizada dentro do projeto e quais os benefícios acadêmicos obtidos. Na Seção 3, apresentam-se brevemente os métodos de PDP adotados e os correspondentes exemplos. Na Seção 4, apresenta-se uma proposta para integração entre TRL, PDP em projetos acadêmicos, novas perspectivas e proposições de trabalhos futuros.

\section{NÍVEIS DE MATURIDADE TECNOLÓGICA OBTIDOS}

O projeto em questão trata de comunicação através do solo (TTE - Through-the-Earth), na qual um transmissor e um receptor ficam, respectivamente, localizados na superfície e no subsolo. De maneira resumida, e sem entrar nos detalhes técnicos, o tema de pesquisa é a investigação do comportamento de um sistema de comunicação capaz de realizar a transmissão e recepção de dados (comunicação bidirecional), através desta camada de solo. Maiores detalhes são apresentados por CARREÑO et al., (2016). Aplicações típicas são comunicações em minas subterrâneas, cavernas e localização de objetos soterrados. Dentro do plano de trabalho do projeto, está proposta a construção de um protótipo que viabilize a prova de conceito em ambiente laboratorial, permitindo assim a aplicação de algumas técnicas de desenvolvimento de produto à pesquisa realizada pelo corpo docente e discente. 
Uma possível maneira de se avaliar o grau de maturidade tecnológica de um determinado produto é sua a categorização dentro da escala TRL. O conceito foi originalmente desenvolvido pela NASA com 7 níveis para o contexto de desenvolvimento tecnológico de sistemas aeroespaciais (SADIN; POVINELLI; ROSEN, 1989), sendo posteriormente expandido e usado atualmente com 9 níveis (HIRSHORN; VOSS; BROMLEY, 2017). Trata-se de uma escala graduada de 1 a 9, sendo o nível 1 associado ao conhecimento dos princípios básicos de funcionamento do produto (físicos, químicos, matemáticos), e o nível 9 associado à disponibilização para o mercado. A Tabela 1 apresenta, de maneira resumida, a escala TRL, seguindo de perto a nomenclatura e definições da norma ABNT correspondente (ABNT, 2015).

TABELA 1 - Níveis de Maturidade Tecnológica

\begin{tabular}{|c|c|}
\hline $\begin{array}{l}\text { Nível de } \\
\text { maturidade } \\
\text { tecnológica }\end{array}$ & Breve descrição \\
\hline TRL 1 & $\begin{array}{l}\text { Princípios de base observados e relatados. Aplicações identificadas, mas não há requisitos de } \\
\text { desempenho. }\end{array}$ \\
\hline TRL 2 & $\begin{array}{l}\text { Conceito e/ou aplicação da tecnologia formulados. Os requisitos são gerais, mas consistentes } \\
\text { com as aplicações identificadas. }\end{array}$ \\
\hline TRL 3 & $\begin{array}{l}\text { Prova de conceito analítica e experimental da função crítica e/ou da característica. Uso de } \\
\text { estudos analíticos, experimentos laboratoriais e medidas. Requisitos de desempenho funcional } \\
\text { estabelecidos. }\end{array}$ \\
\hline TRL 4 & $\begin{array}{l}\text { Verificação funcional em ambiente laboratorial do componente e/ou maquete. Validação de } \\
\text { funcionamento básico dos subsistemas quando integrados. }\end{array}$ \\
\hline TRL 5 & $\begin{array}{l}\text { Verificação em ambiente relevante da função crítica do componente e/ou maquete. Possível } \\
\text { realizar modelo em escala. }\end{array}$ \\
\hline TRL 6 & $\begin{array}{l}\text { Modelo demonstrando as funções críticas do elemento em ambiente relevante. Desempenho do } \\
\text { elemento demonstrado sem ambiguidade, requisitos de desempenho operacional estabelecidos } \\
\text { levando em conta integração no sistema final. }\end{array}$ \\
\hline TRL 7 & $\begin{array}{l}\text { Modelo demonstrando o desempenho do elemento para o ambiente operacional. Demonstrar } \\
\text { que o elemento funciona no ambiente real. }\end{array}$ \\
\hline TRL 8 & Sistema real desenvolvido. \\
\hline TRL 9 & Sistema real demonstrado. \\
\hline
\end{tabular}

Segundo OLECHOWSKI; EPPINGER e JOGLEKAR, (2015), existe uma dificuldade de mapeamento direto entre o os níveis de TRL e o processo de DP, ilustrado de maneira genérica 
na Figura 1. Entretanto, é possível notar que, entre os dois extremos do detalhamento do projeto e na escala TRL, há a menção de protótipos e modelos experimentais. Este ponto em comum sugere uma possibilidade de vínculo entre as duas representações do desenvolvimento de um produto.

Seguindo D'AMICO; O'BRIEN e LARKIN, (2012), as etapas do desenvolvimento de produtos podem ser, grosso modo, categorizadas em três fases: prova de conceito, prototipagem e produção. Por outro lado, a escala TRL pode ser encarada como marcos (milestones) de projeto, ou associados a gates com entregas específicas que permitam caracterizar o alcance de um determinado nível de TRL. Assim, as fases iniciais com foco na prova de conceito estariam vinculadas aos níveis TRL 1 a 3; a fase de prototipagem, abarcando todo o projeto preliminar e detalhado, atingiria TRL 6 e a pré-produção estaria vinculada ao TRL 9.

Neste estudo de caso, a continuidade do projeto por 4 anos permitiu o desenvolvimento de uma série de simuladores e protótipos, além de possibilitar o estabelecimento de uma correlação entre os temas das publicações científicas e os níveis de TRL. A Tabela 2 mostra a relação entre os produtos acadêmicos e a escala TRL.

TABELA 2 - Níveis de Maturidade Tecnológica alcançados dentro do projeto e correspondentes entregas acadêmicas.

\begin{tabular}{|c|c|c|}
\hline TRL & Atividades correspondentes & Produto acadêmico \\
\hline 1 & $\begin{array}{l}\text { Simulações computacionais básicas do canal de } \\
\text { transmissão (solo). Uso de modelos analíticos } \\
\text { disponíveis na literatura. }\end{array}$ & $\begin{array}{l}\text { Artigo científico estilo "survey" em } \\
\text { periódico. Redação inicial de patente. }\end{array}$ \\
\hline 2 & $\begin{array}{l}\text { Simulação de comunicação de dados em canal } \\
\text { modelado. Extração de curvas de desempenho. }\end{array}$ & $\begin{array}{l}\text { Artigos em congresso mostrando taxas } \\
\text { de transmissão possíveis na transmissão } \\
\text { através do solo, assim como as } \\
\text { frequências de transmissão exequíveis. } \\
\text { TCCs com resultados de simulação e } \\
\text { projetos iniciais dos transceptores. }\end{array}$ \\
\hline 3 & $\begin{array}{l}\text { Simulação computacional do sistema de comunicação, } \\
\text { considerando o efeito de ruído antrópico e atmosférico. } \\
\text { Primeiras antenas construídas e testadas em ambiente } \\
\text { laboratorial. Primeiras medições de ruído na superfície. } \\
\text { Geração de sinais utilizando equipamentos de bancada. } \\
\text { Integração inicial entre simuladores e setup } \\
\text { experimental para transmissão de dados. Produção de } \\
\text { simulador contemplando conexão entre múltiplos nós. }\end{array}$ & $\begin{array}{l}\text { Artigos em congresso e revista } \\
\text { apresentando desempenho de sistema } \\
\text { com modelos elaborados do canal, } \\
\text { incluindo simulações estatísticas. } \\
\text { Caracterização laboratorial das antenas. } \\
\text { Duas dissertações de mestrado. Tema } \\
\text { central de tese de doutoramento, } \\
\text { referente à modelagem estatística do } \\
\text { canal. }\end{array}$ \\
\hline
\end{tabular}




\begin{tabular}{|l|l|l|}
\hline TRL & Atividades correspondentes & Produto acadêmico \\
\hline 4 & $\begin{array}{l}\text { Integração entre antenas, sistemas transmissor e } \\
\text { receptor, uso de circuitos ressonantes e sondagem de } \\
\text { canal automatizada. }\end{array}$ & $\begin{array}{l}\text { Artigo com medições de ruído em locais } \\
\text { próximos à UnB. } \\
\text { Artigo apresentado em congresso } \\
\text { Teste do conjunto em ambiente soterrado, como modelo } \\
\text { em escala para a comunicação } \\
\text { andamento). }\end{array}$ \\
$\begin{array}{l}\text { Teste planejado em ambiente relevante (caverna), com } \\
\text { profundidade de } 60 \text { m entre transmissor e receptor. } \\
\text { Etapas iniciais do projeto do transceptor sem } \\
\text { equipamento de bancada. }\end{array}$ & $\begin{array}{l}\text { Em progresso: TCCs com projeto } \\
\text { detalhado de elementos específicos do } \\
\text { sistema (transceptores). Esperado artigo } \\
\text { com as medições no ambiente da } \\
\text { caverna. }\end{array}$ \\
\hline
\end{tabular}

Dos resultados apresentados na Tabela 2, é possível verificar a relevância do uso de simuladores e protótipos para o desenvolvimento da pesquisa e o benefício acadêmico correspondente. Ressalta-se aqui a importância da busca pela concretização do protótipo físico como elemento motivador para os alunos de engenharia, e a possibilidade de emprego de técnicas de DP ao longo da execução das atividades de pesquisa.

\section{FERRAMENTAS DE AUXÍLIO AO DP APLICADAS NO PROJETO DE PESQUISA}

Dentro do projeto TTE, três técnicas tradicionais constantes nos processos de DP foram aplicadas: QFD, implementado pela primeira matriz de desdobramento, a Casa da Qualidade (HoQ -House of Quality) (HAUSER; CLAUSING, 1988); Análise do Modo de Falhas e seus Efeitos (FMEA) (CARLSON, 2012); e, finalmente, Projeto para Montagem (DFA - Design for Assembly) (BOOTHROYD; DEWHURST; KNIGHT, 2001).

O primeiro nível de QFD aplicado ao sistema encontra-se na Figura 2. A HoQ apresentada aqui tem o apenas o intuito de ilustrar o resultado do processo de uso da ferramenta projeto de pesquisa. O processo de construção do mapeamento entre requisitos ou necessidades do "cliente" (aqui o usuário final do produto) e os requisitos técnicos preliminares exigiu a iteração entre vários membros do grupo e de diversas especialidades e o envolvimento de alunos em dois campi diferentes da UnB: Darcy Ribeiro e Gama.

As necessidades foram classificadas em mandatórias, tais como a transmissão e recepção sem fio, alimentação por bateria no equipamento soterrado, portabilidade e segurança. As necessidades esperadas são: leveza, facilidade na instalação e ajuste do posicionamento das antenas, enquanto as desejáveies são basicamente a interface intuitiva e maleabilidade de antena. Os requisitos do produto foram pré-categorizados em potenciais subsistemas 
funcionais:antenas, interface com usuário e transceptor. Realizou-se, ainda, a correlação entre os requisitos de projeto, o "telhado" da casa da qualidade.

\begin{tabular}{|c|c|c|c|c|c|c|c|c|c|c|c|}
\hline \multicolumn{4}{|c|}{ Legendas } & & & & & & & 1 & \\
\hline Requisitos & Relacionamentos & \multicolumn{2}{|c|}{ Correlações } & & & & & & 1 & -1 & \\
\hline $\mathrm{M}=$ mandatório (5) & $2=$ Forte & \multicolumn{2}{|l|}{1 = positiva } & & & & & 1 & 1 & 1 & \\
\hline$E=$ esperado (3) & 1 = Médio & \multicolumn{2}{|l|}{$0=$ neutro } & & & & 1 & 0 & 1 & 1 & \\
\hline \multirow{4}{*}{$\mathrm{D}=$ desejado (1) } & $0=$ Fraco & \multicolumn{2}{|c|}{$-1=$ negativa } & & & 0 & 0 & 0 & 0 & 0 & \\
\hline & & & & & 2 & 0 & 0 & 0 & 0 & 0 & \\
\hline & & & & 1 & 1 & 0 & 1 & 0 & 0 & 0 & \\
\hline & Necessidades & 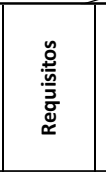 & $\begin{array}{l}\mathscr{W}^{\pi} \\
\sum^{\pi}\end{array}$ & 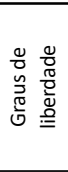 & 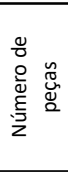 & 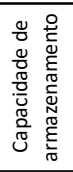 & 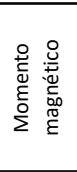 & 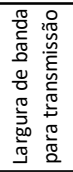 & 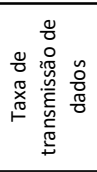 & 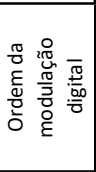 & 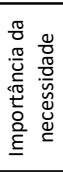 \\
\hline \multirow{3}{*}{ Mecânicas } & Manuseável & $M$ & 2 & 2 & 2 & 0 & 1 & 0 & 0 & 0 & 35 \\
\hline & Montável e desmontável & $E$ & 1 & 2 & 2 & 0 & 0 & 0 & 0 & 0 & 15 \\
\hline & Leve & $\mathrm{D}$ & 2 & 0 & 1 & 0 & 0 & 0 & 0 & 0 & 3 \\
\hline \multirow{3}{*}{ Elétricas } & Alimentado a bateria & $\mathrm{M}$ & 1 & 0 & 0 & 2 & 2 & 0 & 0 & 0 & 25 \\
\hline & Antena circular & D & 0 & 1 & 0 & 1 & 2 & 0 & 0 & 0 & 4 \\
\hline & Ajuste automático de frequência & $\mathrm{D}$ & 0 & 0 & 0 & 1 & 1 & 1 & 1 & 1 & 5 \\
\hline \multirow{2}{*}{ Comunicação } & Transmissão de imagens, voz e texto & $\mathrm{M}$ & 0 & 0 & 0 & 1 & 1 & 2 & 2 & 2 & 40 \\
\hline & Modulação digital & $M$ & 0 & 0 & 0 & 1 & 1 & 2 & 2 & 2 & 40 \\
\hline \multirow[t]{2}{*}{ Interface } & Display, teclado, microfone, alto-falante & $\mathrm{M}$ & 1 & 0 & 2 & 1 & 0 & 0 & 1 & 0 & 25 \\
\hline & & Unidade & $\mathrm{kg}$ & GL & $\mathrm{N}$ & $\mathrm{Ah}$ & Am2 & $\mathrm{kHz}$ & kbits/s & $M$ & \\
\hline
\end{tabular}

FIGURA 2 - Exemplo de aplicação de técnica de QFD em projeto de pesquisa: primeiro desdobramento da HoQ.

Uma segunda técnica aplicada foi FMEA em seu modo mais simples - FMEA de sistema (STAMATIS, 2003) com o intuito de prover robustez ao projeto dos subsistemas. Apenas a título ilustrativo, a Tabela 3 apresenta o número de prioridade de risco (NPR) para algumas falhas sistêmicas e as ações correspondentes para reduzir o seu valor.

TABELA 3 - Estudo FMEA usado no projeto.

\begin{tabular}{|c|c|c|c|c|c|c|c|}
\hline \multirow[b]{2}{*}{ SS } & \multicolumn{3}{|c|}{ Falhas Possíveis } & \multicolumn{4}{|c|}{ Índices } \\
\hline & Modo & Efeito & Causas & $\mathbf{S}$ & $\mathbf{O}$ & D & NPR \\
\hline 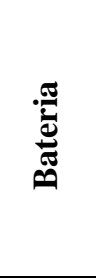 & $\begin{array}{l}\text {-Bateria incapaz de } \\
\text { fornecer energia para o } \\
\text { equipamento. } \\
\text {-Bateria não carrega. }\end{array}$ & $\begin{array}{l}\text {-Equipamento não } \\
\text { liga; } \\
\text {-Equipamento não } \\
\text { realiza comunicação. }\end{array}$ & $\begin{array}{l}\text {-Mau dimensionamento } \\
\text { da capacidade da } \\
\text { bateria; } \\
\text {-Falha no circuito de } \\
\text { alimentação; } \\
\text {-Corrente excessiva. }\end{array}$ & 10 & 2 & 2 & 40 \\
\hline 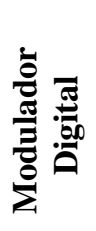 & $\begin{array}{l}\text {-Não realiza } \\
\text { modulação; } \\
\text {-Modulação incorreta; }\end{array}$ & $\begin{array}{l}\text {-Mensagem não é } \\
\text { transmitida; } \\
\text {-Informação } \\
\text { transmitida incorreta; }\end{array}$ & $\begin{array}{l}\text {-Circuito danificado; } \\
\text {-Escolha inadequada de } \\
\text { hardware; }\end{array}$ & 10 & 2 & 2 & 40 \\
\hline$\overline{\frac{a}{a}}$ & $\begin{array}{l}\text {-Não exibe todos os } \\
\text { caracteres; }\end{array}$ & $\begin{array}{l}\text {-Informação } \\
\text { incompleta. }\end{array}$ & $\begin{array}{l}\text { - Manutenção } \\
\text { inadequada; }\end{array}$ & 7 & 1 & 1 & 7 \\
\hline
\end{tabular}




\begin{tabular}{|c|c|c|c|c|c|c|c|}
\hline & $\begin{array}{l}\text {-Não exibe nenhum } \\
\text { caractere; } \\
\text {-Exibe alguns } \\
\text { caracteres errados; }\end{array}$ & -Informação errada; & $\begin{array}{l}\text { - Software } \\
\text { desatualizado; } \\
\text {-Falha na programação. }\end{array}$ & & & & \\
\hline 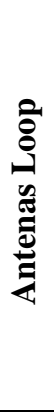 & $\begin{array}{l}\text {-Falha na transmissão; } \\
\text {-Falha na recepção; }\end{array}$ & $\begin{array}{ll}\text {-Informação } & \text { não } \\
\text { recebida; } & \\
\text {-Informação } & \text { não } \\
\text { transmitida. } & \end{array}$ & $\begin{array}{l}\text {-Falha no } \\
\text { direcionamento da } \\
\text { antena; } \\
\text {-Corrente baixa; } \\
\text {-Quantidade de fio } \\
\text { condutor insuficiente; } \\
\text {-Formato do loop } \\
\text { inadequado. }\end{array}$ & 10 & 2 & 1 & 20 \\
\hline 䒿 & $\begin{array}{l}\text {-Fratura de eixo } \\
\text {-Rotação ineficiente } \\
\text { nos elementos das } \\
\text { juntas } \\
\text {-Ajuste insuficiente } \\
\text { entre componentes de } \\
\text { fricção. }\end{array}$ & $\begin{array}{l}\text {-Quebra completa } \\
\text {-Elementos de rotação } \\
\text { travados } \\
\text {-Deformação de } \\
\text { componentes de } \\
\text { ligação. }\end{array}$ & $\begin{array}{l}\text {-Peso superior à carga } \\
\text { máxima } \\
\text {-Corrosão/ degradação } \\
\text { de peças } \\
\text {-Tensões de } \\
\text { Cisalhamento nas juntas }\end{array}$ & 10 & 1 & 1 & 10 \\
\hline
\end{tabular}

Como complemento ao estudo FMEA, elaborou-se um diagrama de árvore de falhas (FTA Fault Tree Analysis) simplificado.

Finalmente, realizou-se um estudo específico para o projeto do suporte das antenas, usando princípios de projeto para montagem (DFA), tendo em vista os requisitos de portabilidade e maneabilidade das antenas, que podem ter dimensões da ordem de 2 metros de diâmetro. Para o suporte, os principais requisitos estabelecidos para análise foram a leveza e a estabilidade, de forma que atendam ao principal objetivo de suportar o peso da antena e ao mesmo tempo permitir fácil locomoção; como requisito de flexibilidade de configuração, adicionaram-se (i) a rotação em torno de dois eixos, permitindo mais possibilidades de transmissão e recepção do sinal, e (ii) suportes com comprimento e altura ajustáveis.

A construção dos protótipos também se mostrou essencial ao emprego das técnicas mencionadas. Um primeiro ponto observado foi a natural divisão dos alunos e professores entre os três subsistemas. Trabalhos de conclusão de curso e de mestrado utilizaram como motivação e justificativa o pano de fundo geral do produto, e dentro de cada trabalho houve projeto, simulação computacional e implementação de cada um dos subsistemas relevantes (antenas, transmissor, canal de transmissão e receptor). A implementação seguiu a ordem cronológica de 
execução de projeto, sendo os trabalhos iniciais voltados para simulação computacional das funcionalidades essenciais de cada subsistema, evoluindo posteriormente para a implementação física e construção dos protótiposmencionados na Tabela 2.

A Figura 4 mostra um dos susbsistemas obtidos pelo projeto, o subsistema de recepão. O resultado final foi obtido após as etapas de projeto, testes em ambiente computacional e testes em conjunto com as antenas.
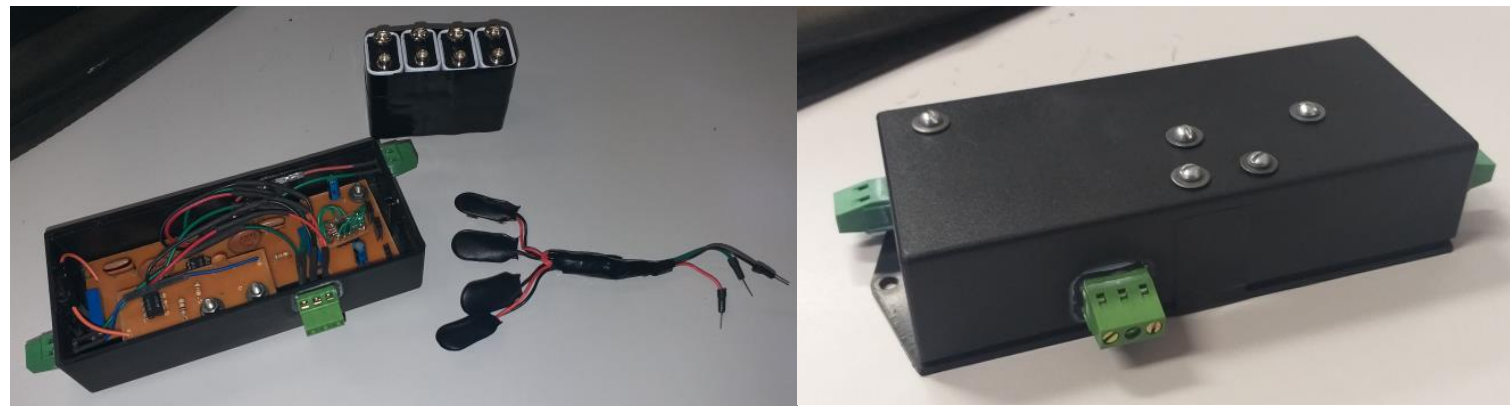

FIGURA 4 - Exemplo re subsistema obtido pelo projeto - circuito de recepção. Esquerda: conjunto com receptor, camos de conexão e bateria. Direita: receptor com invólucro.

A Figura 5 ilustra a evolução temporal do projeto explicitando os níveis de TRL alcançados o alcance dos TRL 3 e 4 só foram possíveis devido à aplicação de uma metodologia sistemática de testes, ao desenvolvimento da integração entre simulador e testbed para ensaios laboratoriais e em campo e ao desenvolvimento de protótipos para os componentes do sistema. A Figura também aponta para a necessidade de manutenção de escopo primário da pesquisa em projetos de maior prazo, de modo a permitir a construção de ferramentas específicas para a realização das atividades de investigação (no caso, simuladores) e o projeto, teste e validação dos protótipos.

Cabe aqui ressaltar que a realização de testes em caverna, simular ao ambiente de minas subterrãneas, pode ser considerado como compoenete importante para obtenção de TRL 5, pois trata-se de teste realizado em ambiente relevante, com condições similares às que seriam encontradas em operação durante o uso. Entretanto, como o teste contempla o uso de alguns subsistemas implementados com equipamento de bancada, optou-se por manter o sistema como um todo no nível TRL 4. 


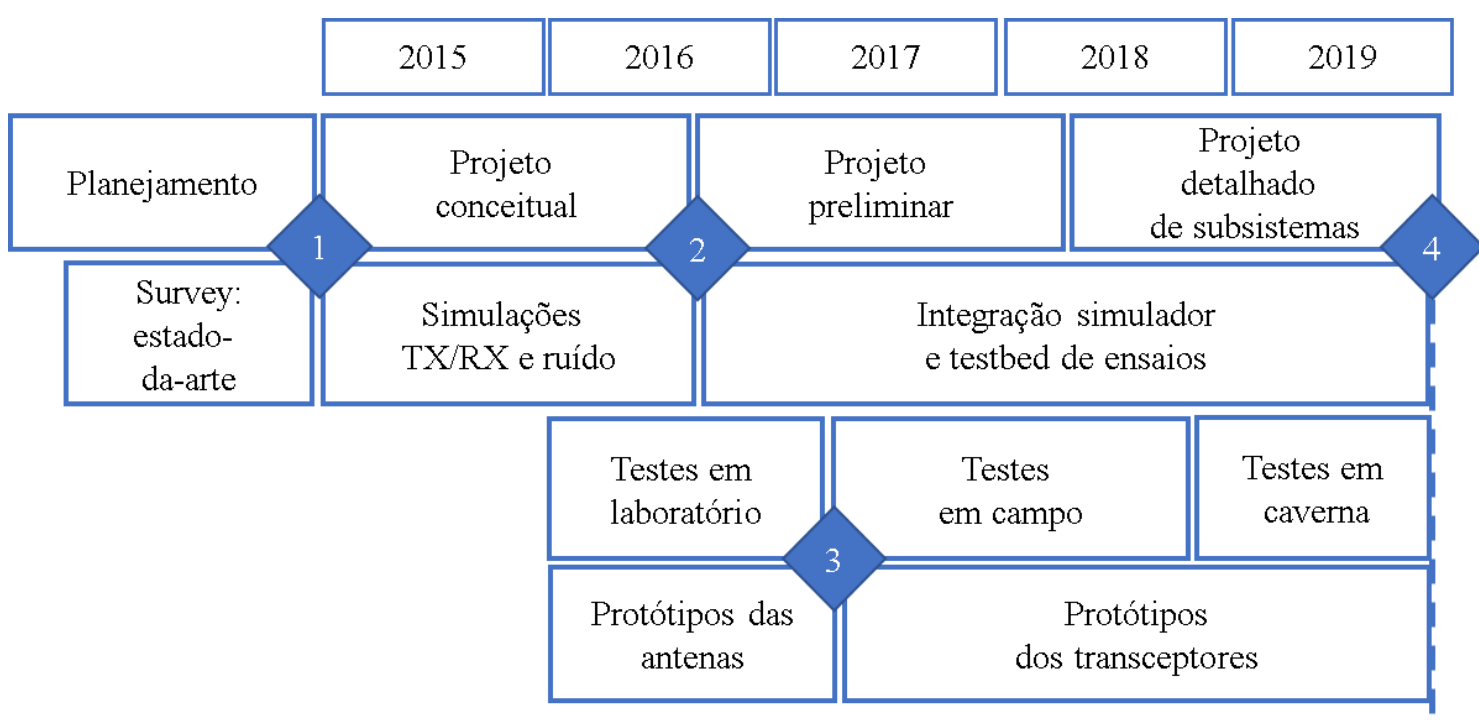

FIGURA 5 - Correlação entre a escala TRL (losangos azuis), as etapas de desenvolvimento abarcadas pelo projeto TTE e o desenvolvimento de testes e protótipos.

\section{DISCUSSÃO E TRABALHOS FUTUROS}

JUAN, WEI e XIAMEI, (2010) apontam uma eventual dificuldade no uso dos níveis TRL para avaliação dos projetos de pesquisa realizados na universidade. Um exemplo é o de uma tecnologia madura, mas não avançada, e que, portanto, não promove competitividade quando transferida ao ator externo. Os autores propõem um incide composto de outros indicadores de maturidade tecnológica para contemplar este e outros aspectos relevantes.

A abordagem aqui apresentada é mais simples: utilizar o TRL como indicador não para medir o sucesso, mas sim para iniciar a iteração entre a universidade e os patrocinadores da pesquisa. O estudo de caso apresentado sugere uma diretriz para planejamento e execução de projetos de pesquisa com viés de desenvolvimento tecnológico: a proposta é indicar no plano de projeto a identificação do TRL atual e a meta de qual seria o TRL alvo a ser obtido ao final da execução do projeto. Pode-se então vincular o nível de TRL desejado (ou possível, dentro das condições específicas de infraestrutura laboratorial disponível) aos protótipos a serem produzidos e às fases específicas de desenvolvimento do produto que sejam de interesse de um eventual patrocinador do projeto.

No caso de projetos com duração além de dois anos, uma maneira de se mitigar os riscos associados ao aporte financeiro é a separação do escopo total em fases atreladas a entregas mapeáveis aos TRL alvo, cada uma com um orçamento específico. O envolvimento próximo 
do corpo de engenharia do patrocinador e a equipe docente e discente, via ferramentas de gestão de projetos, auxilia na manutenção de escopo primário. Por outro lado, a oferta de estágio para alunos de graduação envolvidos também ajuda a minimizar instabilidades inerentes à participação de alunos, sendo também recomendável o vínculo da pesquisa e construção dos protótipos a projetos de Iniciação Científica ou Trabalhos de Conclusão de Curso (TCCs).

A Tabela 3 apresenta uma sugestão de estabelecimento da relação entre as técnicas utilizadas, os protótipos, os TRL desejados e exemplos de produtos acadêmicos produzidos. A possibilidade de produção de artigos e a elaboração de patentes está implícita.

TABELA 3 - Relação entre prototipagem, TRL e entregas acadêmicas para cursos de engenharia.

\begin{tabular}{|c|c|c|c|c|}
\hline $\begin{array}{l}\text { TRL } \\
\text { desejado }\end{array}$ & $\begin{array}{l}\text { Protótipos } \\
\text { utilizados }\end{array}$ & $\begin{array}{l}\text { Ponto de controle } \\
\text { sugerido }\end{array}$ & $\begin{array}{l}\text { Técnicas de DP } \\
\text { aplicáveis }\end{array}$ & $\begin{array}{l}\text { Exemplo de escopo } \\
\text { acadêmico (pós/graduação) }\end{array}$ \\
\hline $1-2$ & $\begin{array}{l}\text { Simuladores e } \\
\text { modelos } \\
\text { comportamentais }\end{array}$ & Relatório técnico & $\begin{array}{l}\text { Análise de } \\
\text { viabilidade técnica, } \\
\text { seleção de variantes }\end{array}$ & $\begin{array}{l}\text { P: modelagem de sistemas } \\
\text { complexos } \\
\text { G: aprimoramento de } \\
\text { simuladores, obtenção de } \\
\text { curvas de desempenho }\end{array}$ \\
\hline $3-5$ & $\begin{array}{lr}\text { Protótipos } & \text { para } \\
\text { testes } & \text { em } \\
\text { ambiente } & \\
\text { laboratorial } & \end{array}$ & $\begin{array}{l}\text { Protocolo de testes, } \\
\text { especificação } \\
\text { detalhada de } \\
\text { requisitos }\end{array}$ & QFD, FMEA, DFX & $\begin{array}{l}\text { P: novas soluções técnicas } \\
\text { para problemas conhecidos } \\
\text { G: projeto de elementos } \\
\text { específicos de componentes } \\
\text { em subsistema, disciplina } \\
\text { laboratorial }\end{array}$ \\
\hline $5-6$ & $\begin{array}{lr}\text { Protótipos } & \text { para } \\
\text { testes } & \text { em } \\
\text { ambiente de uso }\end{array}$ & $\begin{array}{l}\text { Testes } \\
\text { desempenho } \\
\text { detalhados }\end{array}$ & FMEA. FTA & $\begin{array}{l}\text { P: novas técnicas para } \\
\text { integração de sistemas, } \\
\text { novos protocolos de teste e } \\
\text { validação } \\
\text { G: uso correto de } \\
\text { equipamentos complexos, } \\
\text { aprimoramentos pontuais em } \\
\text { sistemas já projetados }\end{array}$ \\
\hline
\end{tabular}

A proposta apresentada, de vínculo explícito do projeto de pesquisa aos níveis TRL aplicáveis tem as seguintes vantagens:

* Possibilita criar um ambiente de pesquisa alinhado com as demandas externas à universidade. O mapeamento inicial dos níveis de TRL e a avaliação do escopo do projeto de pesquisa tende a aproximar a pesquisa em Engenharia das necessidades locais apresentadas pelos patrocinadores, sejam empresas privadas, órgãos governamentais ou agências de fomento. 
* Permite a construção de um relacionamento mais duradouro entre a pesquisa em engenharia e o ambiente industrial. Fases de projeto bem-sucedidas vinculadas aos TRL iniciais podem ser o gatilho para uma nova rodada de desenvolvimento de protótipos, permitindo completar o ciclo acadêmico de dois anos para a formação de mestres e de quatro anos para doutores. Projetos mais duradouros também permitem a estabilidade necessária para a realização de trâmites referentes à escrita de patentes e detalhamento de cláusulas específicas sobre questões de propriedade intelectual.

* Facilita a transferência tecnológica para eventuais empresas encubadas na universidade ou start-ups locais, visto que os marcos TRL já deixam explícito o nível de esforço necessário para a continuidade do projeto fora da universidade.

* O processo é alinhado com a recomendação de boas práticas recomendadas pelo IPEA (RAUEN; BARBOSA, 2019) para realização de encomendas tecnológicas (ETECs) no Brasil.

* A exposição do corpo discente às complexidades inerentes à prototipagem proporciona aumento na maturidade do aluno nos aspectos de fundamentos de metodologias de projeto e desenvolvimento de produto.

Dentre os trabalhos futuros, duas frentes de trabalho associadas ao tema estão planejadas. A primeira é a medição quantitativa do impacto do emprego das técnicas de DP adotadas no projeto (HoQ, FMEA, FTA e DFM). A segunda é avaliar a adoção de outros indicadores para ajudar no processo de decisão no momento de iniciar a iteração entre projetos de pesquisa aplicada e o patrocinador externo. A fim de buscar resolver as limitações conhecidas do TRL (OLECHOWSKI, 2015), os indicadores propostos são o SRL e o IRL (respectivamente, System Readiness Levels e Integration Readiness Levels), em sua conceituação clássica (ROSS, 2016). Não há consenso a respeito dos cálculos desses indicadores: a estratégia para isso seria a aplicação de um algoritmo de normalização (SAUSSER et al, 2009) junto à concepção de DSM do projeto (Design Structure Matrix) (TOMPKINS, 2019).

\section{AGRADECIMENTOS}

Agradecemos ao Instituto Tecnológico Vale (ITV) o apoio financeiro à pesquisa realizada, e aos alunos de graduação e de pós-graduação envolvidos no projeto. 


\section{REFERÊNCIAS}

BACK, N. et al. Projeto integrado de produtos: planejamento, concepção e modelagem. Barueri: Malone, p. $435-482,2008$

Boothroyd, G.; DeWhurst, P.; KNIGHT, W. A. Product Design for Manufacture and Assembly, revised and expanded. [s.1.] CRC press, 2001.

CARLSON, C. Effective FMEAs: Achieving safe, reliable, and economical products and processes using failure mode and effects analysis. [s.1.] John Wiley \& Sons, 2012. v. 1

CARREÑO, J. et al. Through-The-Earth (TTE) Communications for Underground Mines. Journal of Communication and Information Systems, v. 31, n. 1, 2016.

D'AMICO, A.; O'BRIEN, B.; LARKIN, M. Building a bridge across the transition chasm. IEEE Security \& Privacy, v. 11, n. 2, p. 24-33, 2012.

HAUSER, J.R., CLAUSING, D.P. The House of Quality, Harvard Business Review, May-June 1988, pp. 6373.

HIRSHORN, S. R.; VOSS, L. D.; BROMLEY, L. K. Nasa systems engineering handbook (SP-2016-6105), Rev $2,2017$.

JUAN, Z.; WEI, L.; XIAMEI, P. Research on Technology Transfer Readiness Level and Its Application in University Technology Innovation Management. 2010 International Conference on E-Business and EGovernment. Anais.IEEE, 2010

MADUREIRA, O. M. Metodologia do Projeto: Planejamento, Execução e Gerenciamento, $2^{a}$ ed. São Paulo, Blucher, 2014.

OLECHOWSKI, A.; EPPINGER, S. D.; JOGLEKAR, N. Technology readiness levels at 40: A study of stateof-the-art use, challenges, and opportunities. 2015 Portland international conference on management of engineering and technology (PICMET). Anais.IEEE, 2015

RAUEN, A. T.; BARBOSA, C. M. M. Encomendas tecnológicas no Brasil: guia geral de boas práticas. Brasília, IPEA, 2019.

ROSS, S. Application of System and Integration Readiness Levels to Department of Defense Research and Development Defense Acquisition Research Journal, v. 23 n. 3, p. 248-273, 2016

ROZENFELD, H. et al. Gestão de desenvolvimento de produtos: uma referência para a melhoria do processo. São Paulo: Saraiva, 2006.

SADIN, S. R.; POVINELLI, F. P.; ROSEN, R. The NASA technology push towards future space mission systems. In: Space and Humanity. [s.1.] Elsevier, 1989. p. 73-77.

SAUSSER, B.; RAMIREZ-MARQUEZ, J. E.; MAGNAYE, R.; TAN, W. A Systems Approach to Expanding the Technology Readiness Level with Defense Acquisition. School of Systems and Enterprises, Stevens Institute 
of Technology Paper SIT-AM-09-002, 2009.

STAMATIS, D. H. Failure mode and effect analysis: FMEA from theory to execution. [s.l.] ASQ Quality press, 2003.

TOMPKINS, Z., GREEN, M., ROBERTS, B. Improving System Maturity Assessments by Incorporating a Design Structure Matrix. IEEE Transactions on Engineering Management. 2018. Early Access. DOI: 10.1109/TEM.2018.2867440

ULRICH, KARL T.; EPPINGER, STEVEN D. Product Design and Development. $4^{a}$. ed. New York, McGrawHill, 2004. 384p. 